\title{
Análise da fluoretação da água de abastecimento público da zona urbana do município de Campo Grande (MS)
}

\author{
Water fluoridation analysis of Campo Grande (MS) \\ urban zone public supply
}

Bruno Luiz Lessa Bellé ${ }^{1}$

Valéria Rodrigues de Lacerda ${ }^{1}$

Alessandro Diogo DeCarli ${ }^{1}$

Edílson José Zafalon ${ }^{1}$

Paulo Zárate Pereira ${ }^{1}$

\footnotetext{
${ }^{1}$ Departamento de

Abstract The objective of this study was to analyze the fluoride concentration on the water that flows of thetap in theurban area of the city of Campo Grande (MS). For the fluoride concentration analysis, it was collected water samples of 21 schools placed in the 7 sub districts of the city, in 3 different opportunities, was made by the specific electrode method (using an Orion 9609 BN combined fluoride measuring electrode, coupled with an Orion EA-940 digital potentiometer). The results showed that $63.5 \%$ of the water samples presented acceptable fluoride levels (between 0.60 and $0.80 \mathrm{ppm}$ ) and $36.5 \%$, unacceptable levels. In relation to the condition of the collect places, $76.2 \%$ were considered appropriate and $23.8 \%$ were inappropriate.

Key words Fluoride, Water fluoridation, Dental caries
Resumo 0 presente estudo teve por objetivo analisar a concentração de fluoreto na água que flui das torneiras da zona urbana do município de Campo Grande (M S). Para tanto, foram col etadas amostras deágua de 21 escolas situadas nos setesubdistritos da cidade, em três oportunidades diferentes para análise do teor de fluoreto, determinada pelo método do eletrodo específico (medidor de fluoreto combinado Orion 9609 BN , acoplado a um potenciômetro digital EA-940 da Orion). O sresultados mostraram que $63,5 \%$ das amostras coletadas apresentaram níveis aceitáveis (entre 0,6 a 0,8 ppm) defluoreto e 36,5\%, níveis inaceitáveis. Em relação à condição dos locais de coleta, $76,2 \%$ foram consideradas adequadas e $23,8 \%$, inadequadas.

Palavras-chave Fluoreto, Fluoretação, Cárie dentária 


\section{Introdução}

A partir de 1974, a fluoretação das águas de abastecimento público tornou-se obrigatória no Brasil em municípios onde haja Estação de Tratamento deÁgua (ETA), através da sanção da Lei Federal no $6.050^{1}$, de 24 de maio de 1974, regulamentada pelo Decreto Federal no $76.872^{2}$, de 22 de dezembro de 1975. A concentração de fluoreto para cada localidade deveser estabelecida, como controle, em função da média das temperaturas máximas diárias do ar, em graus Celsius $(\stackrel{\circ}{ } \mathrm{C})^{3}$.

O uso do flúor é apontado como a medida de maior impacto para o controle do desenvolvimento da cárie. Embora seu uso isolado não impeça o desenvolvimento da mesma, apenas reduza a sua progressão, o declínio mundial da doença tem sido atribuído ao uso abrangente de uma ou mais formas de sua utilização ${ }^{4}$.

Dentro das recomendações do relatório do Centers for Disease Control and Prevention $(C D C)^{5}$, do ano de 2001, a fluoretação das águas é destacada como a maneira mais segura, efetiva e econômica de prevenção da cárie, abrangendo pessoas de todas as idades e níveis socioeconômicos.

Apesar da doença cárie ser, ainda, um imenso problema desaúde pública, somente a partir década de sessenta começou a ficar nítida a percepção das limitações e da ineficácia do desenvolvimento de refinamentostécnico-científicos às práticas operativas, cedendo espaço à prevenção das doenças e promoção de saúde ${ }^{6}$.

Diante dessa mudança de paradigma, fez-se necessária a implantação de um sistema de vigilância sanitária para a manutenção do teor de fluoreto recomendado, devendo avaliar o risco que a água fluoretada apresenta em relação à fluorose?.

A questão da fluoretação esua expansão à grande parte da população justificam-se pelo quadro epidemiológico que a cárie apresenta no Brasil. Em 2000, o M inistério da Saúde iniciou a discussão sobre a realização de um amplo projeto de levantamento epidemiológico em saúdebucal, hojeconhecido como "SB Brasil - Condições de Saúde Bucal na População Brasileira", com o objetivo de produzir informações sobre as condições de saúde bucal dos brasileiros, subsidiando o planejamento-avaliação de ações nessa área. Diante dos dados obtidos, observou-se que o índice CPO-D em crianças brasileirasna idade-índicede 12 anoséde 2,78, atingindo a meta estabelecida pela Organização M undial de Saúde (OMS) para o ano de 2000.

No Brasil, a fluoretação daágua deabastecimento público teveinício no M unicípio deBaixo Guandu (ES), em 31 de outubro de 1953, utilizando-se o fluossilicato de sódio na proporção de 0,8ppm9.
Porém, na região Centro-O este, os resultados do SB Brasil mostraram redução inexpressiva em relação aos estudos epidemiológicos anteriores realizados pelo M inistério da Saúde. Especificamente na cidade de Campo Grande (MS), em relação ao fluoreto nas águas de abastecimento público, a concentração está sendo avaliada somente pela própria empresa responsável pela ação (Águas Guariroba S.A.); portanto, sendo necessário e de suma importância, o heterocontrole para análise e controle das águas, como ação de vigilância sanitária.

\section{Material e método}

Foi encaminhado um questionário à empresa responsável pelo tratamento das águas do município, Águas Guariroba S.A, com a finalidade de conhecer al guns dos aspectos do processo de fluoretação e evidenciar a atual situação do sistema de abastecimento.

Para obtenção de informações adicionais, foram feitas solicitações a respeito do heterocontrole das águas à Secretaria de Estado de Saúde de M ato Grosso do Sul eà Secretaria Municipal de Saúdedo Município deCampo Grande(MS), além desolicitação ao Instituto Nacional de M eteorologia (INMET) de um laudo com a média das temperaturas máximas diárias de ar, em graus Celsius $\left({ }^{\circ} \mathrm{C}\right)$, do período de 1999 a 2003.

Nesse estudo, os pontos de coleta das amostras foram escolhidos de maneira aleatória nos distritos municipais, de acordo com a divisão da zona urbana do município executada pela Secretaria Municipal de Saúde, de forma que nenhuma região ficasse excluída das análises. Foi desenvolvida a metodologia já consagrada para análise de fluoreto, ou seja, o método do eletrodo específico Orion 9606 BN, semel hante aos estudos desenvolvidos por Ferreira et al. ${ }^{10}$, M odesto et al. ${ }^{11}$, Bastos et al. ${ }^{12}$, Rodrigues et al..$^{13} \mathrm{e} \mathrm{M}$ aia et al..$^{14}$.

As amostras de água do sistema de abastecimento público para verificação das concentrações de flúor foram coletadas dos quatro distritos da cidade de Campo Grande, subdivididos em sete subdistritos. Em cada subdistrito, três escolas representaram os locais de coleta, escol hidos al eatoriamente, totalizando 21 escolas da rede pública de ensino (Figura 1). Essa coleta foi realizada em três momentos diferentes com intervalos de tempo de 72 e 96 horas em relação à primeira coleta, respeitando-se, rigorosamente, o mesmo horário nos pontos predeterminados, perfazendo o total de noventa amostras. 


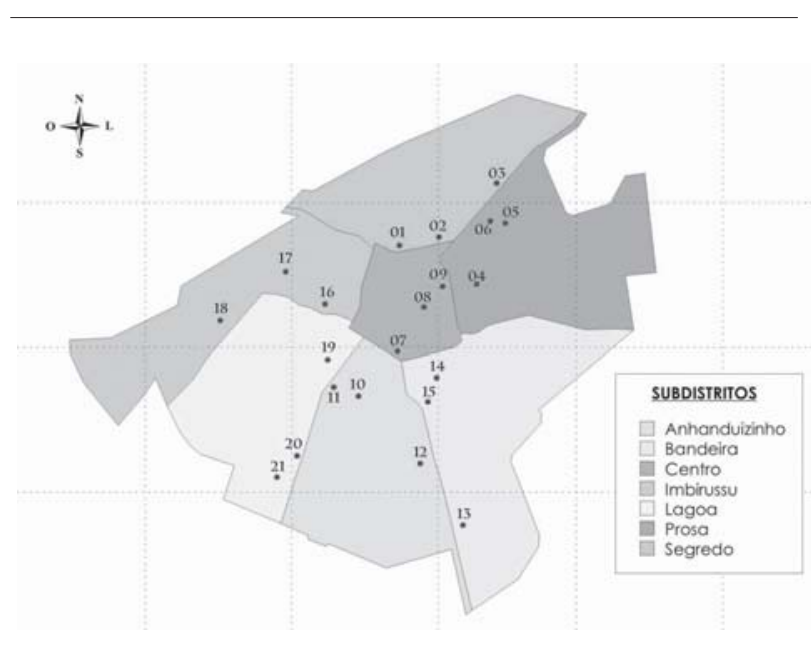

Figura 1. M apa do M unicípio de Campo Grande (MS), Brasil, 2005, com a divisão dos subdistritos e respectivos pontos de coleta.

\section{Resultados}

De acordo com as respostas fornecidas pela companhiaÁguas Guariroba S.A., verificou-seque suas atividades estão regulamentadas conforme a legislação federal em vigor: Lei Federal $n=6.050^{1}$, de 24 demaio de 1974, eDecreto Federal ํㅡ 76.872², de 22 de dezembro de 1975, cujas normas e padrões le gais são estabelecidos pela Portaria $n=635^{3}$, de 26 de dezembro de 1975.

Atualmente, a rede de abastecimento detém uma cobertura populacional em torno de $98 \%$, contando com um sistema composto por três Estações de Tratamento de Água (ETA): Guariroba, Lageado e Desbarrancado, contando ainda com sistemas isolados, ou seja, poços artesianos. 0 composto utilizado para a fluoretação é o ácido fluossilícico, sendo o controle operacional realizado através da análise horária na água tratada, pelo método fotocolorimétrico (Tabela 1).

Segundo a empresa responsável, os bairros onde não há fluoretação das águas encontravamse em fase de implementação, uma vez que esses bairros são abastecidos pelos sistemas de poços artesianos.

Ainda, conformeaSecretaria deEstado deSaúde (MS), está sendo implantado o Sistema de Informações de Vigilância da Q ualidade da Água para o Consumo Humano (SISAGUA), seguindo a Portaria no $518^{15}$, de 25 de março de 2004, etem como objetivos coletar e fornecer informações para a avaliação da qualidade da água, incluindo o heterocontrole da fluoretação ${ }^{16}$ (Tabela 2).

A média das temperaturas máximas anuais, calculadas conformes temperaturas máximas diárias do município de Campo Grande (MS), no período de 1999 a 2003, oscilaram entre 29,4ㅇ C e 31,1 으, segundo o IN M ET.

Tabela 1. Classificação das amostras das águas de abastecimento público de acordo com a concentração de flúor. Campo Grande (M S), Brasil, 2004.

\begin{tabular}{llr}
\hline \multicolumn{1}{c}{ Teor de fluoreto* } & $\mathrm{n}$ & \multicolumn{1}{c}{$\%$} \\
\hline Aceitável (de 0,60 a 0,80 ppm) & 40 & 63,5 \\
Inaceitável (<0,60 e $>0,80$ ppm) & 23 & 36,5 \\
Total & 63 & 100,0 \\
\hline
\end{tabular}

* Dados obtidos em análises, feitas em duplicata de cada coleta, pelo Laboratório deBioquímica da FOP-Unicamp. 
Tabela 2. Classificação das amostras da água de abastecimento público de acordo com o teor de flúor, nos três períodos de coleta (em \%). Campo Grande (MS), Brasil, 2004.

\begin{tabular}{lccc}
\hline \multicolumn{1}{c}{ Teor de fluoreto* } & 1- coleta & 2a coleta & 3a coleta \\
\hline Aceitável (de 0,60 a 0,80 ppm) & 66,7 & 52,4 & 71,5 \\
Inaceitável $(<0,60$ e $>0,80$ ppm) & 33,3 & 47,6 & 28,5 \\
Total & 100,0 & 100,0 & 100,0 \\
\hline
\end{tabular}

* Dados obtidos em análises, feitas em duplicata de cada coleta, pelo Laboratório de Bioquímica da FOP-Unicamp.

A condição do local, em termos da disponibilidade de flúor na água, é avaliada segundo a quantidade de amostras "aceitáveis" e "inaceitáveis". A condição do local foi considerada "adequada" quando, pelo menos, duas das três amostras estiverem qualificadas como "aceitáveis"; do contrário, a condição do local é classificada como "inadequada", como mostra a Tabela 3.

\section{Discussão}

A odontologia iniciou o século XXI com uma situação paradoxal. Se por um lado, o avanço técnicocientífico tentou solver questões de alta complexidade propondo soluções que envolviam engenharia de biomateriais e manipulação de células-tronco, por outro, continuam as pesquisas direcionadas a antigos problemas como, por exemplo, a cárie dentária.

Mesmo o Brasil tendo alcançado os índices preconizados pela OMS em relação ao índice de cárie aos 12 anos, a cárie ainda é considerada um problema de saúde pública, o quejustifica a necessidade de medidas efetivas de prevenção e controle ${ }^{8}$. Entre essas medidas, a fluoretação das águas e abastecimento público tem sido apontada como uma das grandes responsáveis pelo declínio do ata-

Tabela 3. Condição dos locais segundo a concentração de fluoreto nas águas de abastecimento público. Campo Grande (MS), Brasil, 2004.

\begin{tabular}{lcr}
\hline \multicolumn{1}{c}{ Condição do local } & $\mathrm{n}$ & \multicolumn{1}{c}{$\%$} \\
\hline Adequada & 16 & 76,2 \\
Inadequada & 05 & 23,8 \\
Total & 21 & 100,0 \\
\hline
\end{tabular}

* Dados obtidos em análises, feitas em duplicata de cada coleta, pelo Laboratório deBioquímica daFOP-Unicamp. que de cárie, a tal ponto de ser considerado um dos eventos de maior importância na história da odontologia17,18.

Dentreos métodos de utilização do flúor, a fluoretação apresenta-se como o mais seguro, efetivo e econômico para a prevenção da cárie dentária 5,19${ }^{21}$. Entretanto, alguns aspectos requerem atenção quando da implementação do sistema de fluoretação das águas, como, por exemplo, a concentração natural de flúor na água a ser consumida e a vigilância sobre o sistema artificial de fluoretação.

Para garantir os benefícios desse método com segurança em relação à concentração de flúor, recomendou-se oficializar um programa de heterocontrole $^{22}$, a fim de se aproveitar o máximo de benefícios da fluoretação, sendo necessários que os teores deflúor estejam dentro do nível considerado aceitável para cada região, de forma ininterrupta e por longos períodos de tempo $0^{4,23,24}$.

0 presente estudo não teve a intenção de executar o heterocontrole das águas de abastecimento público da zona urbana do município de Campo Grande. Objetivou, sim, verificar o teor deflúor na água de consumo em determinado momento, com o intuito de conhecer a concentração atual. Porém, maior foi o objetivo de despertar a necessidade do heterocontrole. Vale ressaltar que trabaIhos equivalentes já foram desenvolvidos em diversas cidades brasileiras, como Porto Alegre ${ }^{25}$; Ribeirão Preto e região ${ }^{26}$; São Paulo ${ }^{27,28}$; Vitória ${ }^{10}$; Rio de Janeiro ${ }^{11,29}$; Niterói ${ }^{14}$ e Pelotas ${ }^{30}$, entre outros. Entretanto, todos esses trabal hos não substituem o compromisso do Estado no processo de vigilância sanitária, conforme citaram Armonia et al. ${ }^{27}$ e Narvai ${ }^{28}$, ao enfatizarem a importância do heterocontrole, no qual o Estado executa a fluoretação das águas e a prefeitura controla a concentração de fluoreto.

Conhecendo-se os limites recomendados para a concentração de flúor em função da média das temperaturas máximas diárias e a média da temperatura máxima anual de Campo Grande (MS), a concentração de 0,7 ppm de fluoreto é conside- 
rada ótima para o consumo da população campo-grandense. Baseado nesse valor e segundo o critério de amostras aceitáveis ( 0,60 a 0,80 ppm) e não aceitáveis ( $<0,60 \mathrm{ppm}$ e $>0,80 \mathrm{ppm})$, verificou-se que $63,5 \%$ das amostras foram classificadas como "aceitáveis", ou seja, estavam na faixa da concentração ótima. Entretanto, 36,5\% das amostras apresentaram concentrações menores que 0,60 ppm ou maiores que 0,80 ppm, sendo classificadas como "inaceitáveis". M ediante esses dados, podemos considerar a situação aquém do ideal, se comparada com a realidade do município de São Paulo, queteve $97,1 \%$ e $80,0 \%$ das amostras consideradas aceitáveis, conforme os estudos de Armonia et al..$^{27} \mathrm{e} \mathrm{N}$ arvai ${ }^{28}$, respectivamente.

É necessário destacar que 52,2\% das amostras classificadas como "inaceitáveis" foram obtidas em locais com concentrações que coincidem como teor deflúor encontrado nos mananciais $(0,1$ a $0,2 \mathrm{mg} /$ $\mathrm{F} / \mathrm{L})$, o que indica que o distrito $\mathrm{N}$ orte de Campo Grande (MS) é desprovido de um adequado sistema de abastecimento de água fluoretada. Condições semel hantes, nas quais afluoretação não acontece de maneira homogênea, foram encontradas nos estudos de Barros et al. ${ }^{25}$; Spadaro et al. ${ }^{26}$; Ferreira et al. ${ }^{10}$; M odesto et al. ${ }^{11}$; Correia et al. ${ }^{29}$; M aia et al. ${ }^{14}$ e Lima et al..$^{30}$.

\section{Colaboradores}

Os integrantes desse trabalho participaram igualmente de todas as etapas de elaboração.

\section{Agradecimento}

Ao Prof. Dr. Jaime Aparecido Cury, da Faculdade de Odontologia de Piracicaba/Unicamp.
De acordo com a empresa responsável pela fluoretação nos bairros onde a mesma não ocorre, a medida encontra-se em fase de implementação, uma vez que os mesmos são abastecidos pelos sistemas de poços artesianos, o que dificultaria, sobremaneira, o controle operacional do método.

\section{Conclusão}

Em relação aos locais de coleta, verificou-se que dos 21 pontos de coleta na cidade de Campo Grande (MS), 76,2\% foram considerados adequados, enquanto $23,8 \%$ foram considerados inadequados, valores próximos aos encontrados por Armonia et al. ${ }^{27}$ e Narvai ${ }^{28}$ no município de São Paulo (SP).

0 contraste entre um maior número de amostras inaceitáveis, se comparado ao número de locais inadequados, justifica-se pelo fato dequepoucos pontos de coleta concentram a maior parte das amostras inaceitáveis.

Diante dos resultados, verifica-se a premente necessidade de implantação de um mecanismo de heterocontrole, a fim de que se possa monitorar a concentração de fluoreto na água de abastecimento público de Campo Grande, bem como estender o método para toda a população.
Referências

1. Brasil. Lei Federal no 6.050, de 24 de maio de 1974. Diário Oficial da União. Brasília (DF) 197427 mai. [acessado 2005 ago 10]. Disponível em: http:// www.lei.adv.br/6050-74.htm

2. Brasil. Decreto № 76.872, de 22 de dezembro de 1975. Diário Oficial da União. Brasília (DF) 197523 dez. [acessado 2005 ago 10]. Disponível em: http:// www.planalto.gov.br/ccivil_03/decreto/Antigos/ D 76872.htm

3. Brasil. Ministério da Saúde. Portaria no 635, de 26 de dezembro de 1975. Diário Oficial da União. Brasília (DF) 197630 jan. [acessado 2005 ago 10]. Disponível em: http://www.saneago.com.br/novasan/leis/fluor.pdf

4. Cury JA. Uso do flúor e controle da cárie como doença. In: Baratieri LN. Odontologia restauradora: fundamentos e possibilidades. São Paulo: Editora Santos; 2001.p. 31-68.

5. Centers for Disease Control and Prevention. Recommendations for using fluoride to prevent and control dental caries in the United States. M orbidity and mortality weekly report. Atlanta: CDC; 2001.

6. Weyne SC. A construção do paradigma de promoção da saúde: um desafio para as novas gerações. In: Kriger $L$, organizador. Promoção de saúde bucal. 3a ed. São Paulo: Artes M édicas; 2003. p. 1-24. 
7. Koslowski FC, Pereira AC. M étodos de utilização de flúor sistêmico. In: Pereira AC. Odontologia em saúde coletiva: planejando ações e promovendo saúde. Porto Alegre: Artmed; 2003. p. 265-274.

8. Brasil. M inistério da Saúde. Secretaria de Atenção à Saúde. Projeto SB Brasil 2003: condições de saúde bucal da população brasileira 2002-2003. Brasília: M inistério da Saúde; 2004.

9. Emmerich A. O experimento controlado da fluoretação em Baixo Guandu. In: Emmerich A, Freire AS. Flúor e saúde coletiva: 50 anos de fluoretação da água no Brasil. Vitória: Edufes; 2003. p. 44-59.

10. Ferreira HCM, Gomes AM M, Silva KRCS, Rodrigues CRMD, Gomes AA. Avaliação do teor de flúor na água de abastecimento público do município de $\mathrm{Vi-}$ tória - ES. Rev APCD 1999; 53(6):455-459.

11. M odesto A, Tanaka FH R, Freitas AD, Cury JA. Avaliação da concentração de fluoreto na água de abastecimento público do município do Rio de Janeiro. Rev bras odontol 1999; 56(5):217-221.

12. Bastos JRM, Buzalaf M R, Levy FM, Ribeiro TT, Mazzone FHR. Concentração de flúor em água mineral engarrafada e de fontes naturais das cidades de Lindóia, Águas de Lindóia e Serra Negra, Brasil. Rev Fac Odontol Univ Passo Fundo 2001; 6(1):15-19.

13. Rodrigues LKA, Dalcico R, Gomes VE, Zanin ICJ, Nascimento $M M$, Duarte $S$. Análise de flúor em enxaguatórios bucais encontrados no comércio brasileiro e o uso de eletrodo íon-específico. RPG 2002; $9(2): 142-148$

14. M aia LC, Valença AM G, Soares EL, Cury JA. Controle operacional da fluoretação da água de Niterói, Rio de Janeiro, Brasil. Cad. Saude Publica 2003; 19(1):61-67.

15. Brasil. M inistério da Saúde. Portaria no 518, de 25 de março de 2004. Diário Oficial da União. Braślia (DF) 200426 mar. [acessado 2005 ago 10]. Disponível em: http://www.opas.org.br/ambiente/U ploadArq/ PortariaN 0518.pdf

16. Brasil. M inistério da Saúde. Secretaria de Vigilância Sanitária em Saúde. Manual operacional do sistema de informações de vigilância da qualidade da água para consumo humano: SISAGUA. Brasília: Ministério da Saúde; 2003.

17. Loesche W. The 50th anniversary of water fluoridation in Grand Rapids, Michigan. J Public Health Dent 1996; 56(5):233-234.

18. Rozier RG. A new era for community water fluoridation? Achievements after one-half century and challenges ahead. J Public Health Dent 1995; 5(1):3-5.

19. Horowitz HS. The effectiveness of community water fluoridation in the United States. J Public Health Dent 1996; 56(5):253-258.

20. Koch G, Fejerskov O, Thylstrup A. Flúor no tratamento da cárie dentária: implicações clínicas. In: Thylstrup A, Fejerskov 0. Cariologia clínica. 3ạ ed. São Paulo: Santos; 2001. p. 259-282.
21. Murray JJ. 0 uso correto de fluoretos na saúde pública. São Paulo: Santos, 1992.

22. Brasil. Ministério da Saúde. Parecer técnico com o objetivo de esclarecer seu posicionamento técnicocientífico sobre o método de fluoretação da água de abastecimento público. Comitê Técnico-Científico (CTC) de assessoramento à área técnica de saúde bucal do M inistério da Saúde. [acessado 2005 ago 10]. Disponível em: http://dtr2001.saude.gov.br/sps/areastecnicas/Bucal/flúor/água.htm

23. Cortes DF, Ellwood RP, O'Mullane DM, Bastos JR. Drinking water fluoride levels, dental fluorosis, and caries experience in Brazil. J Public Health Dent 1996; 56(4):226-228.

24. Larsen MJ, Bruun C. A química da cárie dentária e 0 flúor: mecanismos de ação. In: Thylstrup A, Fejerskov 0. Cariologia clínica. 3a ed. São Paulo: Santos; 2001. p. 231-258.

25. Barros ERC, Tovo M F, Scapini C. Análise crítica da fluoretação de águas. RGO 1990; 41(5):309-311.

26. Spadaro ACC, Polizello ACM , Carlomagno DN, Alves LAC, Lima SNM. Avaliação do teor de fluoreto na água de abastecimento de cidades na região de $\mathrm{Ri}$ beirão Preto. Rev Odontol USP 1990; 4(3):252-255.

27. Armonia PL, Adde CA, Tortamano N, M elo JAJ. Estado atual da fluoração das águas de abastecimento público no município de São Paulo. Rev Inst Cienc Saúde 1995; 13(2):63-66.

28. N arvai PC. Vigilância sanitária da fluoretação das águas de abastecimento público no município de São Paulo, Brasil, no período 1990-1999 [tese]. São Paulo (SP): Faculdade de Saúde Pública, Universidade de São Paulo; 2001.

29. Correia RP, Ferreira Júnior CD, Maia LC. Análise da fluoretação da água de abastecimento público na zona sul do município do Rio de Janeiro. Pesq Bras Odontoped Clin Integr 2001; 1(2):17-22.

30. Lima FG, Lund RG, Justino LM, Demarco FF, Del Pino $F A B$, Ferreira R. Vinte e quatro meses de heterocontrole de fluoretação das águas de abastecimento público de Pelotas, Rio Grande do Sul, Brasil. Cad. Saude Publica 2004; 20(2):422-429.

Artigo apresentado em 01/09/2006

Aprovado em 25/06/2007

Versão final apresentada em 11/07/2007 